Year:4, Volume:4, Number:7/Yll:4, Cilt:4, Sayı:7 / 2020
$\begin{aligned} & \text { The } \\ & \text { Sociarnal } \\ & \text { Science }\end{aligned}$

DOI Number: 10.30520/tjsosci.658884

\title{
BİR OSMANLI ŞEHRİ OLARAK FİLIBE'NIN KÜLTÜREL VE SOSYAL YAPISI
}

THE CULTURAL AND SOCIAL STRUCTURE OF PLOVDIV AS AN OTTOMAN CITY

\author{
Reyhan Rafet CAN*
}

\section{ÖZET}

Bulgaristan Cumhuriyeti'nin siyasi başkenti Sofya, kültürel başkenti ise Filibe'dir. Filibe aynı zamanda Bulgaristan'ın ikinci büyük şehridir. Toprakları üzerinde tarihin her döneminde çeşitli imparatorluklara ev sahipliği yapmas1, etkileyici bir coğrafyaya sahip olması gibi özelliklerinden dolayı en eski devirlerden beri Balkanlar'da önemli bir merkez halindedir. Bulgaristan Cumhuriyeti'nin güneyinde yer alan Filibe, Yukarı Trakya Ovası'nın verimli toprakları üzerinde kurulmuş, çevresinde Bulgaristan'ın ve Balkan yarımadasının en önemli dağları olan Rodop Dağları, Sredna Gora ve Stara Planina bulunur. Bulgaristan, Yunanistan ve Türkiye arasında sınır oluşturan Meriç Nehri (Maritza) Filibe şehrinden geçerek Türkiye topraklarında Ege Denizine dökülür. Farklı uygarlıklardan kalan eserler Filibe'yi Balkanların en eski ve kültürel mozaiği zengin bir şehir konumuna getirmiştir. Hammadde kaynakları açısından zengin, verimli topraklar üzerinde bulunması, iş gücüne katılım oranının yüksek, sanayi ve ticaretin gelişmiş olması şehrin belli başlı bazı özelliklerindendir. Bu çalışmada Filibe ve yakın çevresinin sosyal ve kültürel yapısı beşerî ve ekonomik coğrafya özellikleri ile birlikte ele alınmıştır.

Anahtar Kelimeler: Filibe, Osmanlı Devleti, Türk Nüfusu, Kültürel ve Sosyal Özellikler.

\begin{abstract}
The diplomatic capital of Bulgarian Republic is Sophia, the cultural capital of Bulgarian Republic is Plovdiv. Besides this, Plovdiv is the second largest city of Bulgaria. The position of Plovdiv has been an important center in the Balkans since the earliest times due to factors such as hosting various empires in its history and having an impressive geography. Located on the fertile soil of the PlovdivThracian Plain in the southern part of the Republic of Bulgaria, it is surrounded by the Rhodope Mountains, Sredna Gora and Stara Planina, the most important mountains of Bulgaria and the Balkan peninsula. Bulgaria, Maritsa River forms the border between Greece and Turkey (Maritza) through the city of Plovdiv, in the historical process contributes to the development of the city. Artifacts from different civilizations made Plovdiv the richest city in the Balkans' oldest and cultural mosaic. It is located on fertile soils rich in raw material resources, high labor force participation rate, developed industry and trade are some of the main characteristics of the city. In this study, the social and cultural structure of Plovdiv and its environs are discussed together with human and economic geography features..
\end{abstract}

Keywords: Plovdiv, Ottoman Empıre, Turkish Population, Cultural and Social Characteristics.

* Dr. Öğr. Üyesi, Osmaniye Korkut Ata Üniversitesi, Kadirli Sosyal ve Beşeri Bilimler Fakültesi, Coğrafya Bölümü, canreyhanrafet@gmail.com, ORCID ID: 0000-0003-2280-9268 


\section{GÍRIȘ}

Balkanlar'da Osmanlı Devleti zamanında Türk varlığı başta Bulgaristan olmak üzere tüm coğrafyada kendini hissettirmiştir. Osmanlı'nın hoşgörüye dayanan politikası kültürel, sosyal ve mimari alanda etkisini göstermiştir. Bulgaristan'da Filibe, Kırcaali ve Ruse gibi şehirlerde Osmanlı izlerini bugün dahi görmek mümkündür. Araştırma sahası olan Filibe ve yakın çevresi $42^{\circ} 9^{\prime}$ kuzey paraleli, $24^{\circ} 45^{\prime}$ doğu meridyenleri arasında yer alır. Şehir farklı tarihlerde birçok medeniyet tarafindan fethedildiği için değişik isimler ile anılmıştır. Bugün Bulgarlar tarafından kullanılan ismi Plovdiv, Türkiye Cumhuriyeti ve Bulgaristan'da yaşayan Türkler şehre Osmanlı’dan miras olarak gördükleri Filibe ismini kullanmakladır.

\section{Filibe Şehrinin Tarihi Gelişimi}

Filibe, Balkan yarımadasının en eski şehirlerinden birisidir. Tarihi, şair Homeros ve tarihçi Herodot'tan daha eski olup Troy ve Miken çağdaşıdır. Roma, Atina ve İstanbul'dan daha eski bir şehirdir. Bugünkü Filibe şehrinin toprakları üzerinde tarih öncesi ilk yerleşimler MÖ. 6 bin yılına dayandırılmaktadır (Naçev, 2004:38). Şehrin ilk sakinleri Trak boyları olmuştur. Traklar şehre Evmolpiya ismini verirken, çeşitli boylar arasında Pulpudepa ismi de kullanılmıştır (Vlasev, 1980:1). Meriç Vadisi ve çevresi bu boylardan olan Diobeslerin yerleşim yerlerindendir (Deliradev, 1953:15). MÖ. IV yüzyılda Makedonya Krallı̆̆ Güneydoğu Avrupa'da hüküm sürmüştür. Makedon Kralı II. Filip, MÖ. 342 yılında Trakları yenilgiye uğratarak tüm Trak yerleşimlerini ve günümüzde eski Filibe'nin bir parçası olan Nebet Tepe'yi ele geçirir (Doyçinov, 2006:14). Trakya'daki Makedon varlığı IV-X yüzyıllar arasında devam etmiştir. Makedonya Krallığı döneminde şehir Trakya’nın ekonomik ve politik merkezi haline gelmiş ve yeni kaleler inşa edilmiştir. Roma döneminde Filipopol (Filibe) ve çevresi acımasız ve amansız savaşlarının merkezi haline gelmiştir. MÖ. XV-XI yüzyıllar arasında Bessaların başlatmış olduğu Vologes ayaklanması Romalılar tarafından bastırılmıştır.

MS. 26 tarihinde Traklar, Filibe'nin kuzeyinden Stara Planina'ya kadar olan yerlerde ayaklanmışlar ancak bu ayaklanmalar her seferinde bastırılmıştır. MS. 45 yılında Filibe'de Trak varlığını imparator Claudius sona erdirdikten sonra bölgeye Roma İmparatorluğu hâkim olmuştur. MS. 46 yılında Filibe şehrinde yerleşimler üç tepe üzerinde yoğunlaştı̆̆ 1 için şehre üç tepeli şehir anlamına gelen Trimontsium adı verilmiştir. Şehir Roma hükümdarlığ1 döneminde Trakya'nın en önemli ve en büyük metropollerinden birisi haline gelmiştir. Trakya'da ilk bronz paranın basıldığı yer burada olmuştur. III. yüzyılın ortalarında Got boyları Tuna Nehri'ni geçerek, şehri yağmalamış ve yakmıştır. Bu yıkım sonucunda 100000 kişi hayatını kaybetmiştir (Petkov, 2009:132). Roma İmparatorluğunda Hristiyanlığın resmi din olarak kabul edilmesinden sonra, Filibe ve çevresinde manastır ve kiliselerin yapımına öncelik verilmiştir. İmparatorluğunun 395 yılında ikiye ayrılmasından sonra Filibe, Roma'nın batısında Bizans sınırları içerisinde kalmıştır. Şehir, batıdan Tuna'yı aşarak saldırılar düzenleyen barbar boylarına karşı üç asır boyunca Trakya'nın merkez şehri ve önemli bir geçiş alanı görevini üstlenmiştir. Bu dönemde Bizans İmparatoru Justinian (527-565), Filibe sınırlarını da içine alacak şekilde 35 kale ve duvar inşa ettirmiştir. Avarlar 584 yılında şehri ele geçirmek için saldırılar düzenlemişler ancak başarılı olamamışlardır. VI. yüzyılda şehre Popıldin / Plıdin adı verilmiştir (Kuradjiev, 1990:80).

Han Tervel zamanında (701-718) Filibe, Bulgarlar ve Bizanslılar arasındaki savaşların merkezi haline gelmiştir. VII. yüzyılın ortalarında Bizans İmparatoru V. Konstantin, Trakya'daki varlığını güçlendirmek için şehir çevresinde askeri gücünü arttırmıştır. Bulgar 
Hanı Krum'un 812 yılında Bizanslıları yenilgiye uğratmasından sonra Filibe ve çevresindeki Bizans nüfusu göç etmiştir. Tsar Petır zamanında Filibe Rafızîlerin merkezi haline gelmiştir. XI. yüzyılda Filibe ve çevresi Katolik mezhebinden olan Bulgarların akınına uğramıştır. İmparator I. Aleksi Komnin, Bulgarların akınını ve şehre yerleşmelerini önlemek amacıyla Aleksipol ismini verdiği yeni surlar inşa ettirmiştir (Rakovski ilçesinde bulunur). Filibe'de Latin askerlerinin varlığ 1096 tarihinden itibaren başlamıştır. Haçlı seferlerine katılan askerler Via Militaris yolunu kullanarak Belgrat ve İstanbul'a ulaşmışlardır. I. Haçlı Ordusu 1096 tarihinde şehirden geçerek Kudüs'e ulaşmıştır. III. Haçlı seferinde şehir Latin askeri tarafindan kuşatılır ve ele geçirilir. Tsar Kaloyan önderliğinde Bulgar kuvvetleri ile Latin kuvvetleri arasında 1205 yılında yapılan savaşın sonucunda şehir Kaloyan tarafından ele kuşatılmıştır. Latin kuvvetleri 1208 tarihinde Tsar Boril ile yaptıkları savaşta, daha önce kaybettikleri toprakları ele geçirir. Klotnitsa savaşında Tsar II. İvan Asen Filibe'yi kendi yönetimi altına almıştır (Gyaurovo, 1899:27).

Filibe'nin Osmanlı topraklarına katılması 1363 tarihine rastlamaktadır. Osmanlı kuvvetleri Edirne'nin fethinden sonra, I.Murad'ın emriyle Edirne'yi kuzeyden emniyet altına almak için Lala Şahin Paşa komutasındaki ordu Filibe'yi ele geçirmiştir. 1877-78 Osmanlı Rus savaşı sonrasında Filibe, önce yeni oluşturulan Şark Rumeli vilayetince, ardından Bulgar preslerince ele geçirildi (Yumerov, 2014:195). Şehirde 1878 tarihinde yapılan seçimler sonucunda 41 Bulgar, 5 Türk, 13 Yunan, 2 Ermeni, 2 Musevi toplam 63 kişi meclise girmiştir. Filibe'de ilk seçilmiş belediye başkanı Kostaki Peev'dir. Şehirde yöneticilik yapmış olan ilk ve tek Türk belediye başkanı ise Hafız Ahmet Efendidir.

\subsection{Osmanlı Şehri Filibe}

Plovdiv 1371 yılında Osmanlı İmparatorluğu'nun yönetimi altına girdikten sonra Filibe ismini almıştır. Bu isim antik Filipopol isminin devamı niteliğindedir. Şehir Sultan I. Murat Hüdavingarın (1362-1389) komutanlarından olan Lala Şahin Paşa tarafından kuşatılmıştır. Şehir metropoliti Manuil can kayıplarının önüne geçmek, tarihi bina ve yapıların yıkılmasını önlemek amacıyla şehir anahtarının Sultan I. Murad'a verilmesini emretmiştir. Osmanlı mimari etkisinin şehirde kendini hissettirdiği dönem Sultan II. Murat (1421-1451) döneminde olmuştur. Bu dönemde Cuma ve İmaret Camileri yaptırılmıştır. Cuma Camisi bugün şehir merkezinde Knyaz I. Aleksandır Caddesi’nde bulunmaktadır (Fotoğraf 1).

Cami dönemin padişahına hitaben Muradiye Camisi, Büyük Cuma Camisi (merkez, cumalı) veya Cuma Camisi olarak anılmıştır (Kesyakova, Pişev, Şivaçev,Petrova, 1999:111). II. Murat'ın padişahlığının son döneminde şehirde yeni bir ibadet merkezi yapılmıştır. Cami, Şebabettin Paşa Camisi olarak anılmış daha sonra ise Imaret Camisi adını almıştır (Velçev, 2005:26). Şahabettin Paşa'nın türbesi İmaret Camisi'nin güney kısmında yer alır (Fotoğraf 2). Süreç içinde Cuma Camisi ve çevresinin bulunduğu saha hızla gelişerek kent merkezi haline gelmiştir. Caminin bulunduğu yerden Meriç Nehri'ne kadar olan sokaklar Uzun Çarşı olarak isimlendirilmiştir. Bu sokaklar aynı zamanda gündelik yaşamın yoğun olduğu ve ticaretin geliştiği yer olarak da bilinmekteydi (Fotoğraf 3).

Evliya Çelebi Filibe şehrinde yer alan esnaf ve Uzun Çarşı’yı 1651 yılında şu şekilde tasvir etmiştir:

Sekiz yüz seksen dükkândır. Köprübaşından ta Ulu Cami’ye varıncaya kadar bin altmış adım uzunluğunda geniş bir caddedir ki, baştanbaşa eski usul üzere döşelidir. Bu ana caddenin iki tarafı kat kat büyük dükkânlarla süslü olup uzun bir çarşıdır. Orta halli olan 
esnaf, haline göre akça, gökçe fakat temiz elbise giyer (Zillioğlu ve Temelkuran, 1986:299).

Çarşıda sayısız zanaat atölyeleri ve ticaret dükkânlar yer alırdı. Bu çarşı boyunca Kurşum Han, Gavaz Han, Karaul Han, Panair Han bulunmaktaydı. Çarşının doğusunda zanaat mahallesi olarak ün salmış Kanana, büyük ve heybetli yapıların yer aldığı kapalı Pazar Bezistan, büyük hamam Tahtakale, irili ufaklı birkaç mahalle camisi bulunurdu (Kesyakova, Pişev, Şivaçev, Petrova, 1999:113,115,116). Osmanlı İmparatorluğu döneminde (XVI - XVII) inşa edilmiş olan ticari ve kültürel yapıların büyük bir kısmı günümüzde ya tahrip edilmiş ya da yerlerinde başka yapılar bulunmaktadır (Tablo 1). Çok az kısmı günümüze kadar sağlam kalabilmiştir. Sağlam kalan yapılar ise Cuma ve İmaret Camisi, Saat Kulesi ve Mevlevihanedir (Fotoğraf 4).

Tablo 1. Osmanlı Döneminde Şehirde İnşa Edilen Yapılar

\begin{tabular}{|c|c|c|c|c|c|c|c|}
\hline \multicolumn{7}{|c|}{ Osmanlı Döneminde İnşa Edilen Eserler } & \multirow{2}{*}{$\begin{array}{l}\text { Günümüze } \\
\text { Gelen } \\
\text { Eserler } \\
\text { İmaret Cami }\end{array}$} \\
\hline Ulu Cami & $\begin{array}{l}\text { Hafiz } \\
\text { Efendi } \\
\text { Cami }\end{array}$ & $\begin{array}{l}\text { Kurşum } \\
\text { Han }\end{array}$ & $\begin{array}{l}\text { Çifte } \\
\text { Hamam }\end{array}$ & $\begin{array}{l}\text { İğne Hoca } \\
\text { Cami }\end{array}$ & $\begin{array}{l}\text { Musala } \\
\text { Cami }\end{array}$ & $\begin{array}{l}\text { Mevlevih } \\
\text { ane Cami }\end{array}$ & \\
\hline $\begin{array}{l}\text { Aladja Mescit } \\
\text { Cami }\end{array}$ & Çukur Cami & $\begin{array}{l}\text { Gavaz } \\
\text { Han }\end{array}$ & $\begin{array}{l}\text { Hünkar } \\
\text { Hamam }\end{array}$ & $\begin{array}{l}\text { Hafiz } \\
\text { Rasim } \\
\text { Cami }\end{array}$ & $\begin{array}{l}\text { Amber } \\
\text { Gazi } \\
\text { Cami }\end{array}$ & $\begin{array}{l}\text { Demircil } \\
\text { er Cami }\end{array}$ & Cuma Cami \\
\hline $\begin{array}{l}\text { Amber Kadi } \\
\text { Cami }\end{array}$ & $\begin{array}{l}\text { Tabakhane } \\
\text { Cami }\end{array}$ & $\begin{array}{l}\text { İmaret } \\
\text { Cami }\end{array}$ & $\begin{array}{l}\text { Kazasker } \\
\text { Hamam }\end{array}$ & $\begin{array}{l}\text { Konak } \\
\text { Cami }\end{array}$ & $\begin{array}{l}\text { Bey } \\
\text { Mescit } \\
\text { Cami }\end{array}$ & $\begin{array}{l}\text { Hoca } \\
\text { Zayde } \\
\text { Cami }\end{array}$ & Saat Kulesi \\
\hline $\begin{array}{l}\text { Cesur Başı } \\
\text { Cami }\end{array}$ & $\begin{array}{l}\text { Süpgürge } \\
\text { Cami }\end{array}$ & $\begin{array}{l}\text { Cuma } \\
\text { Cami }\end{array}$ & $\begin{array}{l}\text { Eni } \\
\text { Hamam }\end{array}$ & $\begin{array}{l}\text { Taş Köprü } \\
\text { Cami }\end{array}$ & $\begin{array}{l}\text { Kairpiç } \\
\text { Mahalle } \\
\text { Cami }\end{array}$ & $\begin{array}{l}\text { Kaşkaden } \\
\text { Cami }\end{array}$ & \\
\hline $\begin{array}{l}\text { Gül-Mahalle } \\
\text { Cami }\end{array}$ & $\begin{array}{l}\text { Sincirli } \\
\text { Bunar Cami }\end{array}$ & $\begin{array}{l}\text { Saat } \\
\text { Kulesi }\end{array}$ & $\begin{array}{l}\text { Çelebi } \\
\text { Kadı } \\
\text { Hamam }\end{array}$ & $\begin{array}{l}\text { Said } \\
\text { Mahmut } \\
\text { Cami }\end{array}$ & $\begin{array}{l}\text { Kumrulu } \\
\text { Cami }\end{array}$ & $\begin{array}{l}\text { Bey } \\
\text { Mescit } \\
\text { cami }\end{array}$ & \\
\hline
\end{tabular}

Kaynak: Yordan Velçev, Gradıt İli Mejdu İztoka İ Zapada (XIV-XVII), İzdatelstvo Janet, Sofya 2005, s. $26,80,81,92$.

XV-XVIII yüzyıllar arasında Filibe, kültürel ticari ve idari merkez olarak varlığını sürdürmüştür. Osmanlı yönetimi döneminde Filibe çok nüfuslu ve çok dilli şehir özelliğini korumuştur. Bulgarlar, Yunanlar ve Ermeniler azınlık olarak varlığını sürdürürken, İspanya'dan göç ettirilen Yahudiler XVI. yüzyılda şehre yerleştirilmiştir. XVII. yüzyılın sonuna doğru şehirde Bulgar nüfusu sistemli olarak artmıştır.

\section{Filibe'de Türk Nüfusu}

Bulgaristan'ın 2018 yılı verilerine göre toplam nüfusu 7000039, Filibe şehrinin nüfus ise 346893'dır. Bu nüfusun \% 9,4‘ü Türk’tür. Türk nüfusu 1881 yılında 1779, 1883 yılında ise 
5558 kişiydi (Andrey Panşev, Stefan Şivaçev, Elena Kesyakova, 1998:40). Bulgaristan'da 1880-1970 yılları arasında 747000 Türk başta Türkiye olmak üzere çeşitli ülkelere yerleşmiş, 1985-2000 yılları arasında ise başka ülkelere göç eden Türklerin sayıs1 330000 olmuştur. Günümüzde Bulgaristan'da kalan Türkler ise Doğu Rodoplar, Ludogorie, Doğu Koca Balkan bölgelerinde yer alan il ve ilçelerde yaşamaktadır. Türk nüfusun $\%$, 1 'i şehirlerde, geri kalanı ise köylerde ikamet etmektedir. Bu nüfusun yoğun olduğu şehirler ise Kırcaali, Momçilgrad, Razgrad, Ruse, Şumen ve Filibe'dir.

Filibe şehrinde Türk nüfusunun geçmişi Sultan I. Murat ve onun varisi olan Beyazıt dönemine kadar uzanmaktadır. Türkler bugün daha çok Stariyat Grad Filibe (Eski Şehir Filibe) olarak isimlendirilen alana yerleşmiş bulunmaktadır. XVII. yüzyılda Osmanlı İmparatorluğu'nda başlayan gerileme başta bölge olmak üzere tüm Balkanlarda kendini hissettirmiş̧ir. Bunun sonucu olarak XVII. yüzyıldan başlamak üzere XVIII. yüzyıla kadarki süreçte Türk nüfusunda azalma Bulgar, Yunan ve Ermeni nüfusunda ise artış yaşanmıştır. Nüfustaki hızlı değişim yerleşme coğrafyasını da etkilemiştir. Osmanlı İmparatorluğu döneminde Türk nüfusun yoğun olduğu Karşıyaka, Maraşayi, Rusin Mahala, Kamenitsa gibi yerler Bulgaristan'ın bağımsızlığından sonra Bulgar nüfusun yoğun istilasına uğramıştır.

\section{Filibe Şehrinin Sosyal ve Kültürel Yapısı}

Filibe şehir yerleşmesine ait ilk bilgiler 1489 yllna aittir. Bu tarihte toplam 30 mahallenin 26'sında Müslümanlar ikamet ederken 4 mahallede Bulgarlar ikamet etmekteydi. Bu mahallelerde toplam 1025 ev bulunmaktaydı. Bu evlerin 892'sinde Müslüman, 97'si Hristiyan, 36'sinda Roman yaşamaktaydı. Filibe'de 1640 yılında 23 Türk, 1 Ermeni, 1 Yahudi, 5 Bulgar ve 1 Yunan mahallesi bulunmaktaydı (Gençev 2007: 26,29). Filibe şehir yerleşmesini Evliya Çelebi 1651 yılında Seyahatname adlı eserinde şu şekilde tasvir etmiştir;

Filiboz sahrasının taa ortasında, Meriç Nehri'nin güney kıyısında Çakıltepe, Boztepe, Canbaz Tepesi, Saray Tepesi, Nöbet Tepesi, Saat Tepesi, Pınarak Tepesi, Gözcü Tepesi, Valeli Tepesi adı verilen dokuz tane yamru-yumru boz boz kayalı dere ve tepeler arasında ve tepelerin zirvelerinde kat kat, boy boy, kargır, bağl1-bahçeli, altl1-üstlü hepsi kızıl kiremit ile örtülü büyük saraylar ile güzel evler vardır. 23 İslam Mahallesi, 7 adet Latin, Sırp, Bulgar, Yahudi ve Rum mahallesi vardır. Frenk Mahallesi yoktur. Mahallelerin başlıcalar: Saat, Boztepe, Canbaztepe, Saray, Nöbet, Pınar, Gözcü, Valeli, Eskicami, Şahabettin, Karşıkasaba mahalleleridir (Zillioğlu ve Temelkuran, 1986:299).

Şehir planı ile ilgili ilk resmi çalışmayı 1892 yılında Yosif Şnider yapmıştır. Şnider'in yapmış olduğu şehir planında 32 ana meydan, 399 sokak ve çoğu Türk ismiyle anılan 40 mahalle bulunmaktaydı (Albadjiev, 2000:11). Bu planda tren garı ile Vasil Aprilov, Ruski, İvan Vazov ana caddeleri birbirine yakın konumda tasarlanmıştır (Fotoğraf 5).

Tablo 2. Filibe Şehrinde 1371-1885 Tarihleri Arasında Türkler Tarafindan Kullanılan Mahallelerin İsimleri

\begin{tabular}{|l|l|}
\hline \multicolumn{1}{|c|}{ Mahalle İsmi } & \multicolumn{1}{c|}{ Bulunduğu Yer } \\
\hline Pazar içi mahallesi & $\begin{array}{l}\text { Günümüzde Nebet Tepe'nin kuzeyinde, Sveti Konstantin ve Elena } \\
\text { kilisesine yakın alanda bulunmaktadır. }\end{array}$ \\
\hline Koç Hüseyin mahallesi & $\begin{array}{l}\text { Bugün Starinna sokağından, Sveti Nedelya Kilisesi’ne kadar olan } \\
\text { bölümdür. }\end{array}$ \\
\hline
\end{tabular}




\begin{tabular}{|c|c|}
\hline Küçük Laut mahallesi & $\begin{array}{l}\text { Yeni mahallenin sonundan güneydeki Kamenitsa tesisine kadar olan } \\
\text { bölümdür. }\end{array}$ \\
\hline Yüskülbeç mahallesi & Nebet Tepe'nin doğu eteklerinin altında bulunmaktadır. \\
\hline Çohadji mahallesi & Djanbaz Tepe'nin güney eteklerinde bulunmaktadır. \\
\hline Hisariçi mahallesi & Sveti Bogoroditsa Kilisesi'nin batı kısmında bulunan alandır. \\
\hline Pulat mahallesi & $\begin{array}{l}\text { Taksim Tepe'nin güneybatısından merkez sokağına kadar olan } \\
\text { bölümdür. Bugün bu alan Knyaz Aleksandır Sokağı olarak } \\
\text { isimlendirilmiştir. }\end{array}$ \\
\hline İbn-i Kasım mahallesi & $\begin{array}{l}\text { Djanbaz Tepe'nin doğu eteklerinden P. R. Slaveykov sokağına kadar } \\
\text { olan bölümdür. }\end{array}$ \\
\hline Büyük Laut mahallesi & Sveti Petka Kilisesi'nin güney bölümünde bulunmaktadır \\
\hline Gül mahallesi & Asenovgrad karayolunun başlangıcında bulunmaktadır. \\
\hline Tahtakale & Günümüzde Benkovski sokağının olduğu bölümdür. \\
\hline Kaya Medjit mahallesi & Erkek Lisesi I. Aleksandır'ın yakınında bulunmaktadır. \\
\hline Keçeci Eni Bey mahallesi & $\begin{array}{l}\text { Sveti Nedelya Kilisesi’nden Meriç Nehri'nin kuzeyine kadar olan } \\
\text { bölümdür. }\end{array}$ \\
\hline Tabak hisar mahallesi & Meriç nehrine yakın bulunmaktadır. \\
\hline Hacı Hasan mahallesi & $\begin{array}{l}\text { Roman Mahallesidir. İztok ve Velişki Sokakları arasında yer } \\
\text { almaktadır. }\end{array}$ \\
\hline Cami Kebir mahallesi & Eski Milli kütüphaneye yakın kurulmuştur. \\
\hline Said Mehmet Efendi mahallesi & Meriç Nehri’nin güneyinde yer almaktadır. \\
\hline Hafiz Efendi mahallesi & Karlovo karayoluna yakındır. \\
\hline Tepealtı mahallesi & Djambaj Tepenin güneydoğusunda yer almaktadır. \\
\hline Müselle mahallesi & Koço Çestemenski ana meydanına yakın kurulmuştur. \\
\hline Barsak ve Kirpiç mahallesi & $\begin{array}{l}\text { Sveti Arhangel Muhail mahallesine yakın kurulmuş olan roman } \\
\text { mahalleleridir. }\end{array}$ \\
\hline Kanana mahallesi & Perunika, Abadjı ve Dökmedjiev sokakları arasında kurulmuştur. \\
\hline
\end{tabular}

Kaynak: Nikola Albadjiev, Plovdivska Hronika (Filibe’nin Kısa Kroniği) İzdatelstvo Letera, Plovdiv 2000, s. 11.

Bulgaristan'ın bağımsızlığından önce (1908) şehirde gündelik hayatın ve ticaretin geliştiği en önemli yerler Cuma Camisi'nin bulunduğu meydan, Uzun Çarşı ve Meriç Nehri çevresiydi. Yeni şehir planında ise bu bölgelerin fonksiyonel özelliği ortadan kaldırılmış, en önemli yerler Knyaz Aleksandır ve İvan Vazov sokakları olmuştur. Filibe'de 1884-1939 tarihleri arasında nüfusun büyük kısmı Saray, İnvaliden, Hristo Botev, Borislav, Belomorski, Küçük Paris, Sıdiyski, Kamenitsa, Gladno Pole ve Karşıyaka mahallerinde yoğunlaşmıştı. Prof. Herman Yanzen 1942 yılında yeni bir şehir planı hazırlamıştır. Stoyko Stoykov, Boris Markov ve K. Boyadjiyev'in 1947 yılında yaptığı yeni şehir planında 30 bin kişilik stadyum, yeni ana caddeler, sokaklar, eğitim-öğretim kurumları bulunmaktaydı. İ. Popov tarafından 1965 yılında yapılan şehir planında Trakya, Kamenitsa, Gagarin Smirnenski mahalleleri, Mimar V. Rangelov tarafindan 1968 yılında kamu binaları, 1969 yılında Mimar M. Mileeva milli kütüphane, 1977 yllında Mimar V. Kolarova ve L.Velçeva Roma stadyumunun bulunduğu merkez sokağını yeniden çizmişlerdir (Fotoğraf 6). Filibe şehir planı ile ilgili en son çalışma 1997 yılında V. Donçev tarafından yapılmıştır. 
Filibe'de eğitim ve öğretim alanında ilk çalışma Vilko Kurmoviç ve Vilko Theoderoviç tarafindan 1850 yılında yapılmıştır. Bugün üç tepe üzerinde yer alan ve 1868 yılında açılan J 1 toto Uçilişte olarak isimlendirilen lise binası şehrin modern anlamda eğitim veren ilk okuludur (Fotoğraf 7). Günümüzde bu okul müzik, dans ve sanat akademisi olarak kullanılmaktadır. Şehirde ilk Bulgar Kütüphanesi olan İvan Vazov 1869 yılında açılmıştır. Filibe'de 1885 yılında 6 Bulgar, 4 Yunan, 3 Türk, birer Ermeni ve Yahudi okulu bulunmaktaydı. Filibe'nin en prestijli eğitim-öğretim kurumu ise Mijkata Gimnaziya olarak isimlendirilen ve 1885 yılında açılan okuludur. Şehirde 1930'lu yılların sonunda 24 ilkokul ve 7 lise bulunmaktaydı. Bu yıllarda Türk okullarında eğitim-öğretim devam etmekte, ancak okullardaki öğrenci sayısı oldukça yetersizdi.

\section{Stariyat Grad Plovdiv ''Eski Şehir Filibe”,}

Eski Filibe olarak isimlendirilen sit alanı üzerindeki ilk yerleşim yerleri binyıl başlarında, neolitik devirde Nebet Tepe, Djambaz Tepe ve Taksim Tepe üzerinde kurulmaya başlanmıştır. Nebet Tepe'de yapılan arkeolojik kazılarda yedi metre derinlikte, 12 farklı kültür katına ait arkeolojik kalıntılara rastlanılmıştır. Nebet Tepe ikinci binyılın sonunda Traklar'ın yerleşimine sahne olmuştur. Traklar tepenin etrafina gözetleme kuleleri yapmışlar ve bulundukları yere Evmolpiya ismini vermişlerdir. Eski Filibe olarak isimlendirilen alanda bulunan tepeler 1956 yılında Kültür Bakanlığı tarafından arkeolojik ve tarihi öneme sahip sit alanı ilan edilmiştir (Ovçarova, 2006:4). Bu sit alanında Bulgaristan sınırları içerisinde I. ve II. yüzyıldan kalan en önemli antik kalıntılar bulunmaktadır. Eski Filibe olarak isimlendirilen alanın kuzey kısmında sosyal, dini ekonomik ve politik faaliyetlerin sürdürüldüğü çeşitli binaları bulunmaktadır. Stariyad Grand heykelleri, tarihi evleri, camileri, kiliseleri, çeşmeleri ile iç ve dış turizm açısından önemli bir merkezdir (Fotoğraf 8). Antik tiyatro ve Hisar kap1 geçmişten günümüze kalan en önemli yapılardan bir diğeridir (Fotoğraf 9,10). Hisar kap1 İmparator Justinyan zamanında (V-VI) yapılmıştır. Eski Filibe de dikkat çeken yerlerden bir diğeri de tarihi evlerdir. Bugüne kadar $200 \mathrm{ev}$ restorasyon edilip Eski Filibe atmosferi içerisinde yerini almıştır.

Eski Filibe olarak isimlendirilen tarihi-arkeolojik alanda yer alan tarihi evlerin bir kısmında Arkeoloji Müzesi, Havacılık Müzesi, Etnografya Müzesi, Doğa ve Bilim Müzesi, Tarih Müzesi bulunmaktadır. Bulgaristan'ın en eski müzelerinden birisi olan Arkeoloji Müzesi'ndeki eserlerin çoğunluğu Antik Yunan'dan kalmadır. Bulgaristan'da uçak sanayisinin tüm tarihçesini Havacılık Müzesi'nde görmek mümkündür. Etnografya müzesi XIX. yüzyılda inşa edilmiş olup günümüzde müzede 40000'e yakın parça bulunmaktadır. Filibe Tarih Müzesi 1951 yılında Filibe ve yakın çevresinde hüküm süren farklı uygarlıklara ait olan tarihi kalıntılarının araştırılması ve korunması amaç ile kurulmuştur.

\section{SONUÇ}

Bulgaristan'1n kültürel başkenti olan Filibe'de arkeolojik ve kültürel öneme sahip eserlerin sayısı fazladır. Ancak kültürel varlıkların korunması yönünde atılan adımlar yetersizdir. Şehirde bulunan Nebet Tepe üzerindeki yapıların bir kısmı onarımdan geçmiş bir kısmı ise tamamen terk edilmiştir. Bu durum Osmanlı'dan kalan mirasın yok olmasına neden olmaktadır. Bunun önüne geçmek için Plovdiv Belediyesi ve ilgili makamların hassasiyetle çalışması gerekmektedir. İmaret Camisi'nin bahçesinde bulunan ve Şehabettin Paşa'ya ait olan türbe günümüzde bakımsız durumdadır. Türbenin Bulgaristan Baş Müftülüğü ve 
Türkiye'den ilgili makamların işbirliği ile onarımı oldukça önemlidir. Osmanlı mirası Mevlevihane'nin restoran olarak kullanılıyor olması, şehirde Osmanlı'dan kalma eserlere önem verilmediğinin bir göstergesidir.

\section{KAYNAKÇA}

Albadjiev, Nikola, Plovdivska Hronika (Filibe'nin Klsa Kroniği), İzdatelstvo Letera, Plovdiv 2000.

Deliradev, Pavel, Prinos Kım İstoriçeskata Geografiya Na Trakiya, İzdatelstvo Bılgarska Akademiya Na Naukite, Sofya 1953.

Doyçinov, Doyçin. Plovdiv Ot A Do Ya, İzdatelstvo Tempodem Eood, Plovdiv 2006.

Gençev, Nikolay, Vızrojdentskiyat Plovdiv Prinos Vıv Bılgarskoto Duhovno Vizrajdane, İzdatelstvo İztok-Zapat, 2007.

Gyaurovo, A.T, Kratki Beleşki Za Minaloto I Segaşnoto Na Grad Plovdiv, Peçatnitsa Trud, Plovdiv 1899.

Kesyakova, Elena, Pişev, Aleksandır, Stefan, Şivaçev, Nedyalka Petrova, Kniga Za Plovdiv, İzdatelstvo Poligraf, Plovdiv 1999.

Kostov, H.Dimitır. Antiçna İstoriya Na Grad Plovdiv (Ot Nay Dılboka Drevnost Do Padane Pod Osmansko Vladiçestvo), İzdatelstvo Janet 45, Plovdiv 2008.

Kuradjiev, Svetlin, Gorno-Trakiyska Nizina, İzdatelstvo Narodna Prosveta, Sofya 1990.

Naçev, Nasko, Plovdiv Rehberi, İzdatelstvo Business Agency, Plovdiv 2004.

Ovçarova Petya, Stariyad Grad Plovdiv (Eski Şehir Filibe),İzdatelstvo Unikard OOD, Plovdiv 2006.

Panşev Andrey, Şivaçev Stefan, Kesyakova Elena, Plovdiv Po Pltya Kım Moderniya Svyat (Modern Dünyaya Doğru Filibe), İzdatelsvo Pitişta, Plovdiv 1998.

Petkov, T, Plovdiv I Plovdivska Oblast, İzdatelstvo Trud, Sofya 2009.

Vlasev, Georgi, Horisyan, Topos, Plovdiv I Plovdivski Okrlg, İzdatelstvo Sofya Pres, Sofya 1980.

Velçev, Yordan, Gradıt İli Mejdu İztoka İ Zapada (XIV-XVII), İzdatelstvo Janet 45, Sofya 2005.

Yumerov, Aydan, 'Bir Osmanlı Şehri Olarak Filibe ve Filibe Mevlevihanesi', Mütefekkir, Aksaray Üniversitesi İslami İlimler Fakültesi Dergisi, I/I, (2014), s. 193-211.

Zillioğlu, Mehmet, Temelkuran, Tevfik, Evliya Çelebi Seyahatnamesi (III - IV Cild), Üçdal Basımevi, İstanbul 1986. 


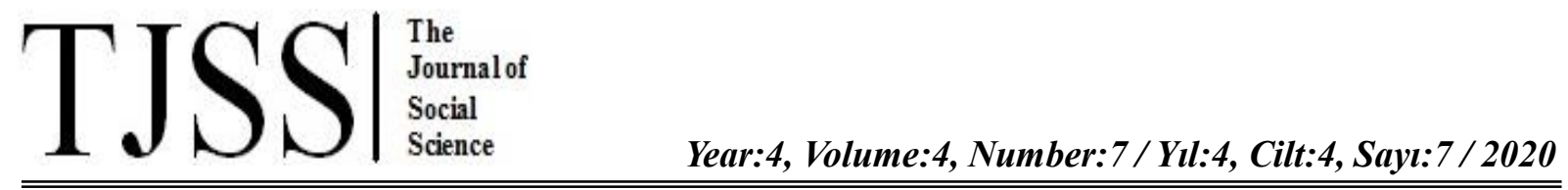

Ek 1.

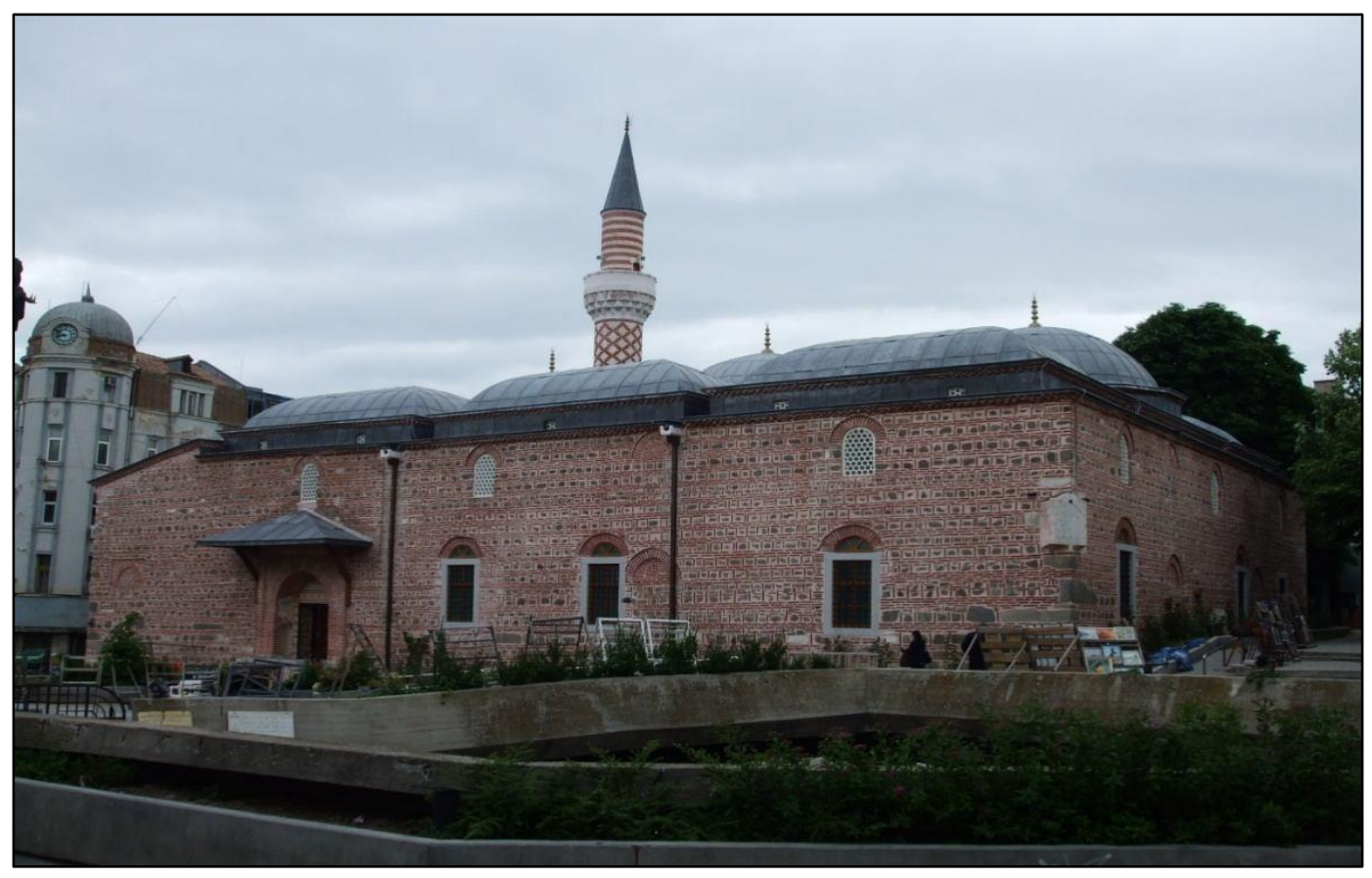

Fotoğraf 1. Filibe şehrinde bulunan Cuma Camisi'nden bir görünüm.

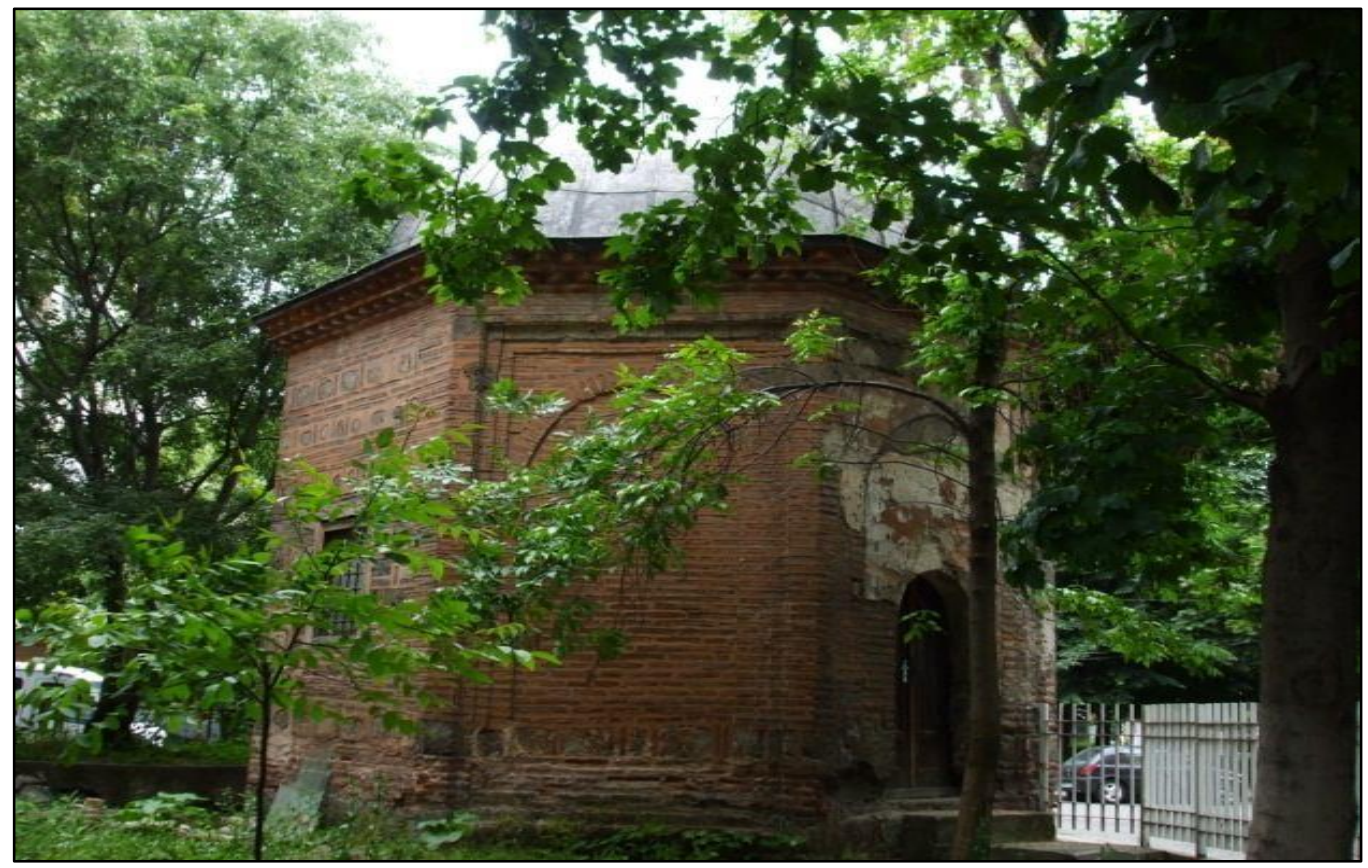

Fotoğraf 2. Şahabettin Paşa türbesinden bir görüntü. 


\section{TJSS}

Year:4, Volume:4, Number:7 / Yul:4, Cilt:4, Sayı:7 / 2020

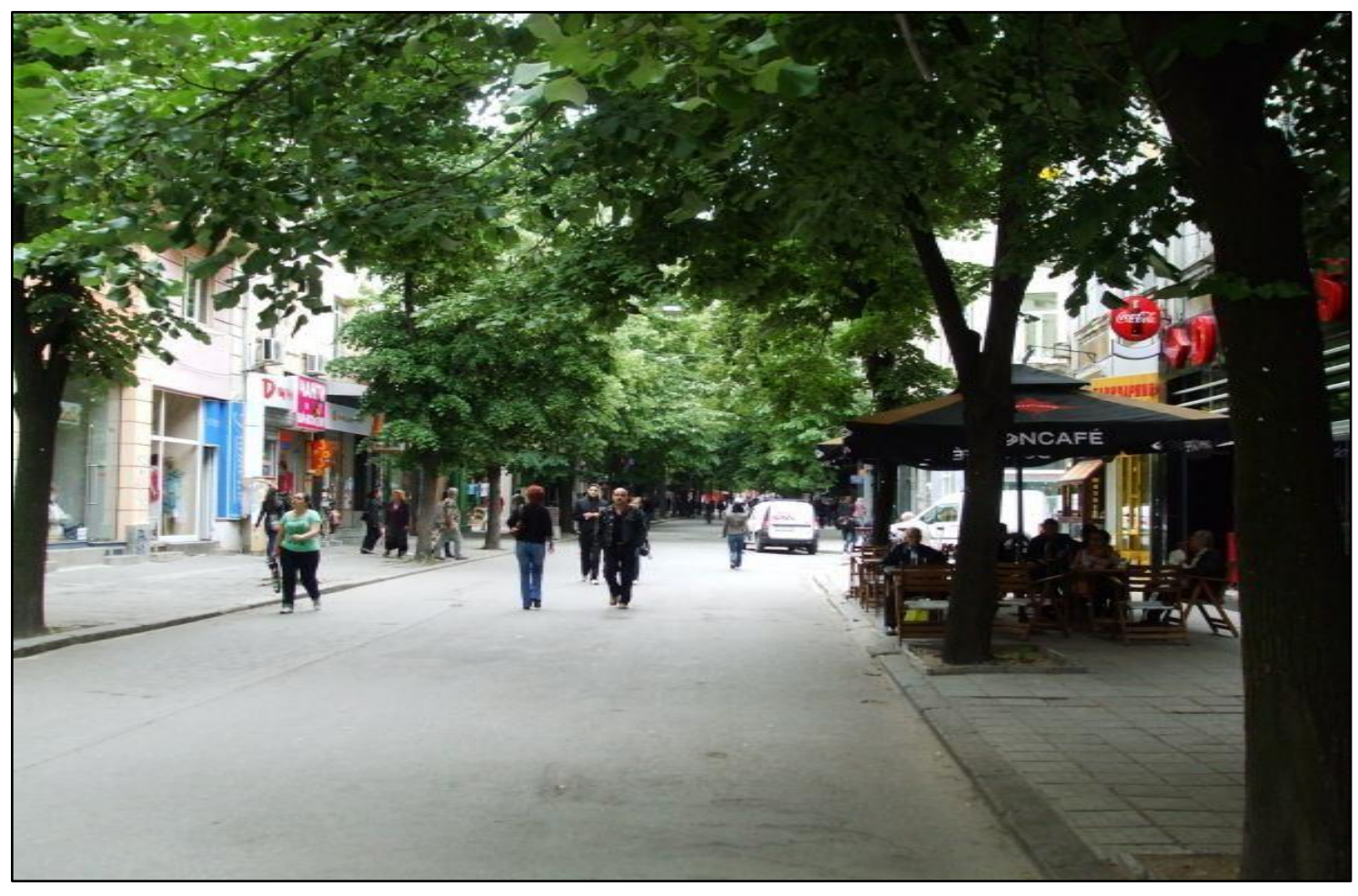

Fotoğraf 3. Osmanlı Devleti zamanında Türklerin yoğun olarak yaşadığı ve ticaretlerini yaptıkları Uzun Çarşı'dan görünüm.

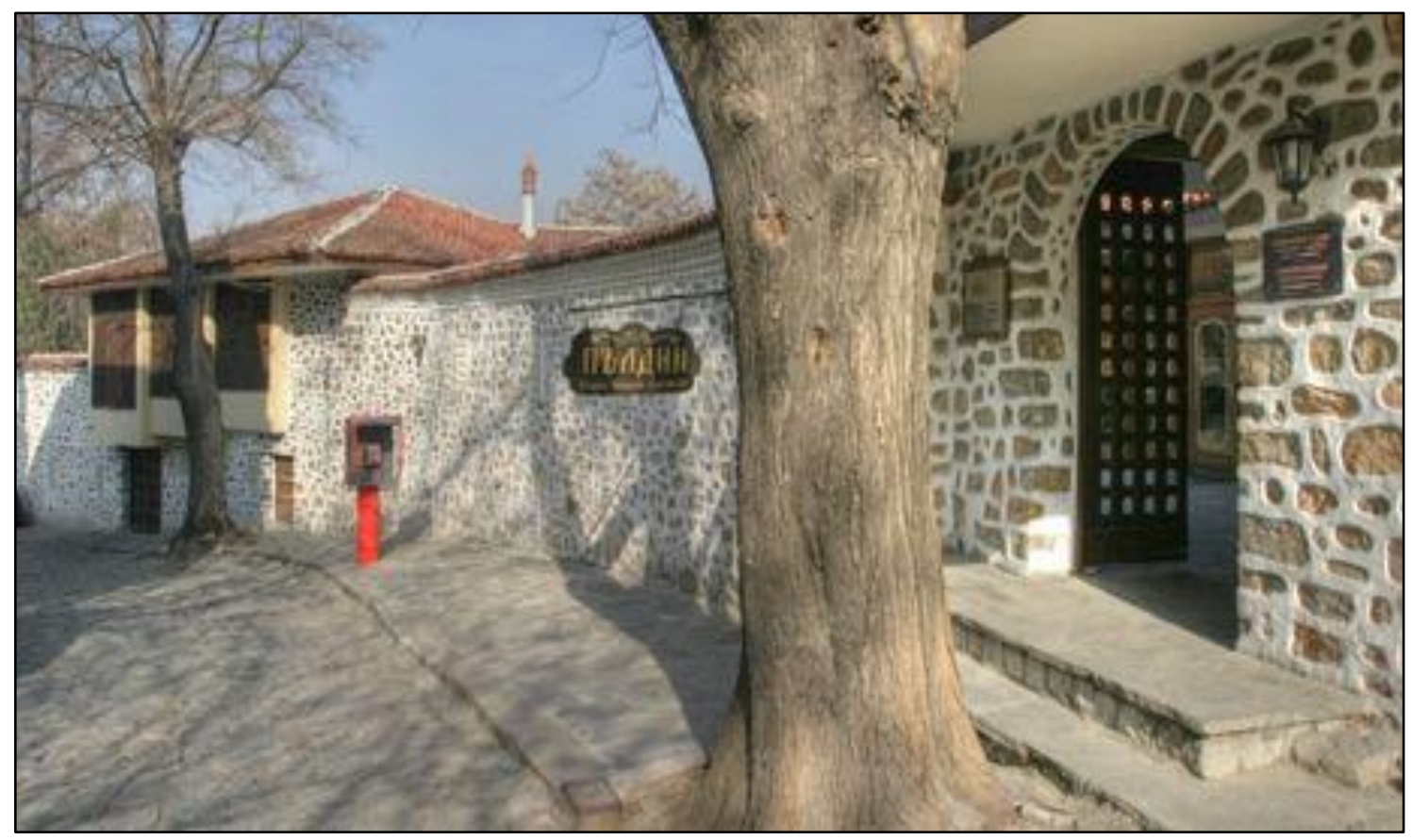

Fotoğraf 4. Günümüzde restoran olarak kullanılan Mevlevihane'den bir görünüm. 


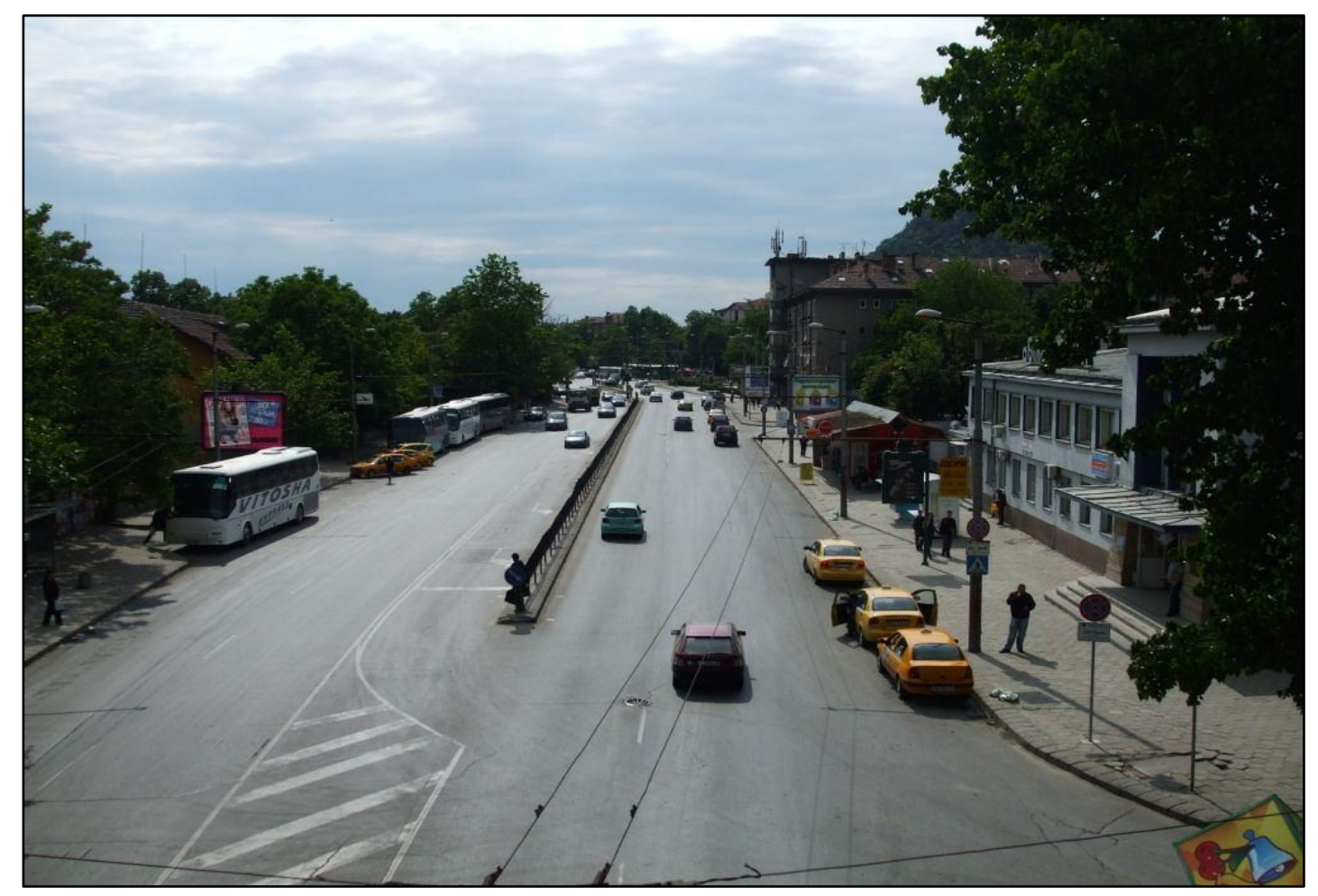

Fotoğraf 5. Vasil Aprilov Bulvarı'ndan bir görünüm.

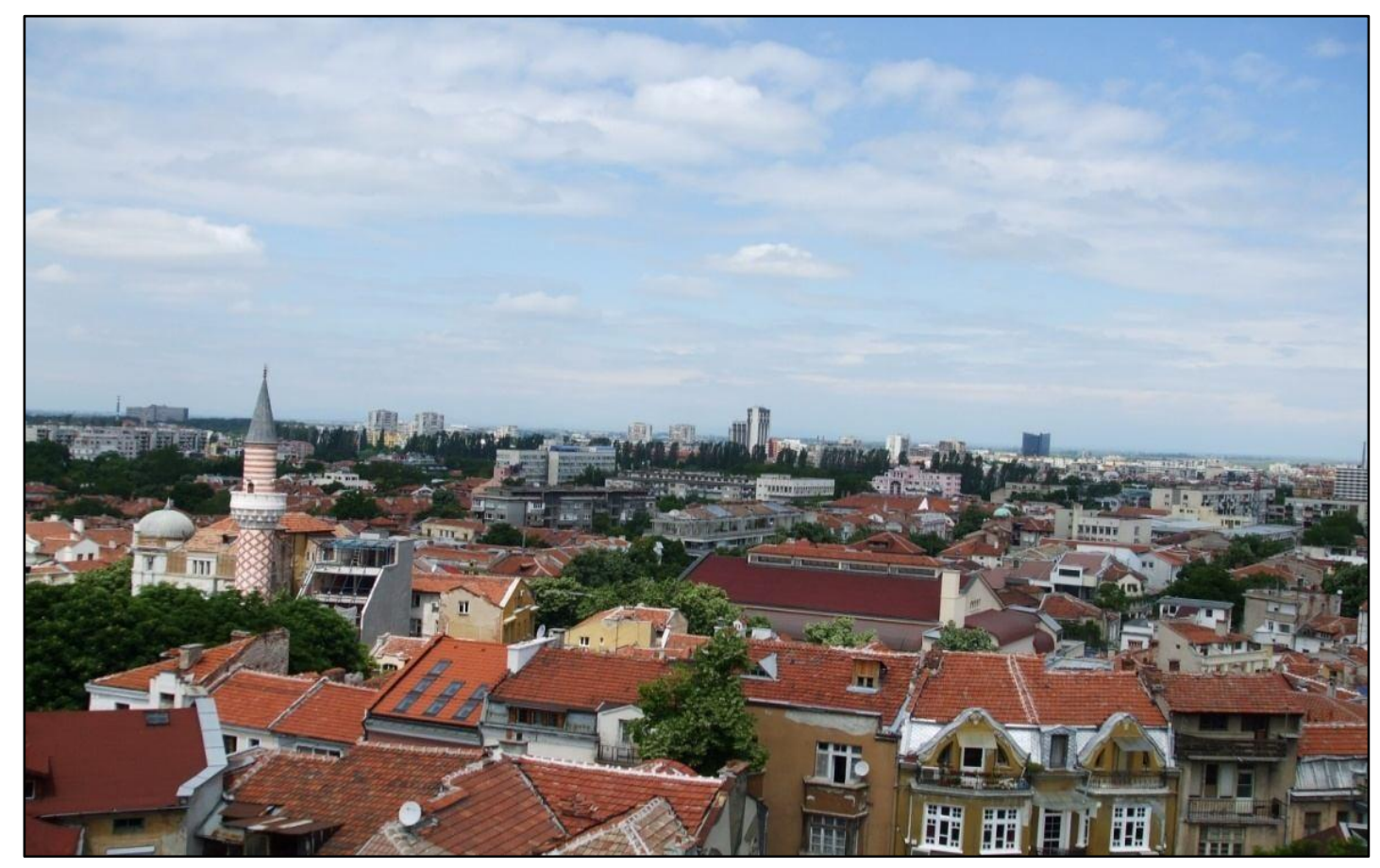

Fotoğraf 6. Tsentralen Mahallesi’nden bir görünüm. 


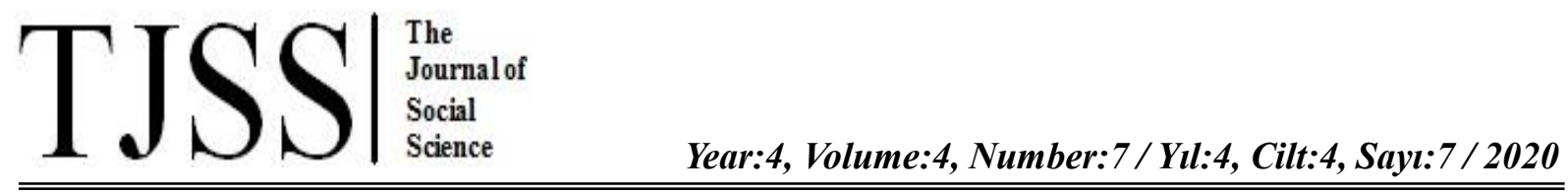

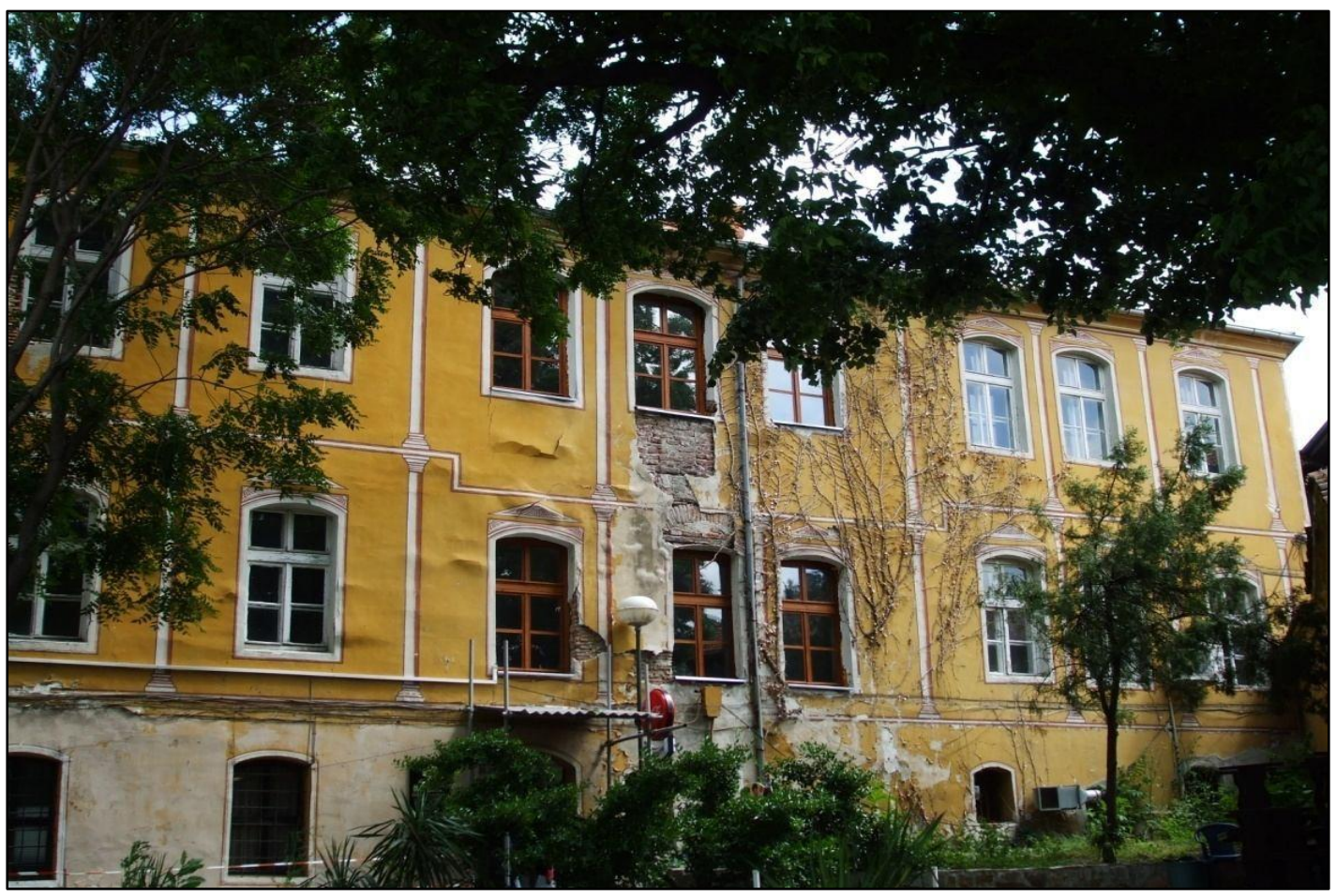

Fotoğraf 7. Filibe'de açılan ilk okul olan Jıltoto Uçilişteden (Sarı Okuldan) bir görünüm.

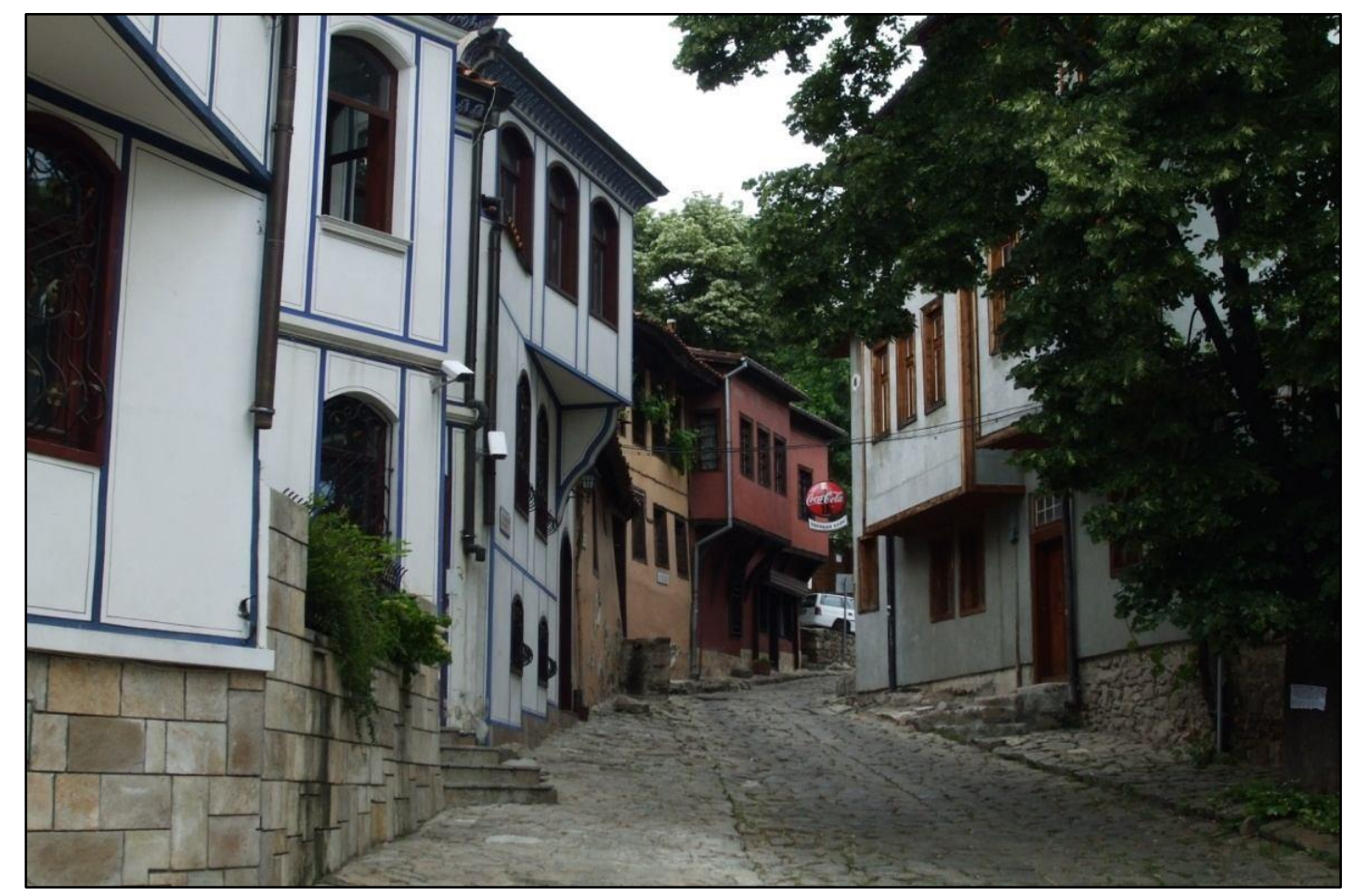

Fotoğraf 8. Eski Filibe sokaklarından bir görünüm. 


\section{TJSSS}

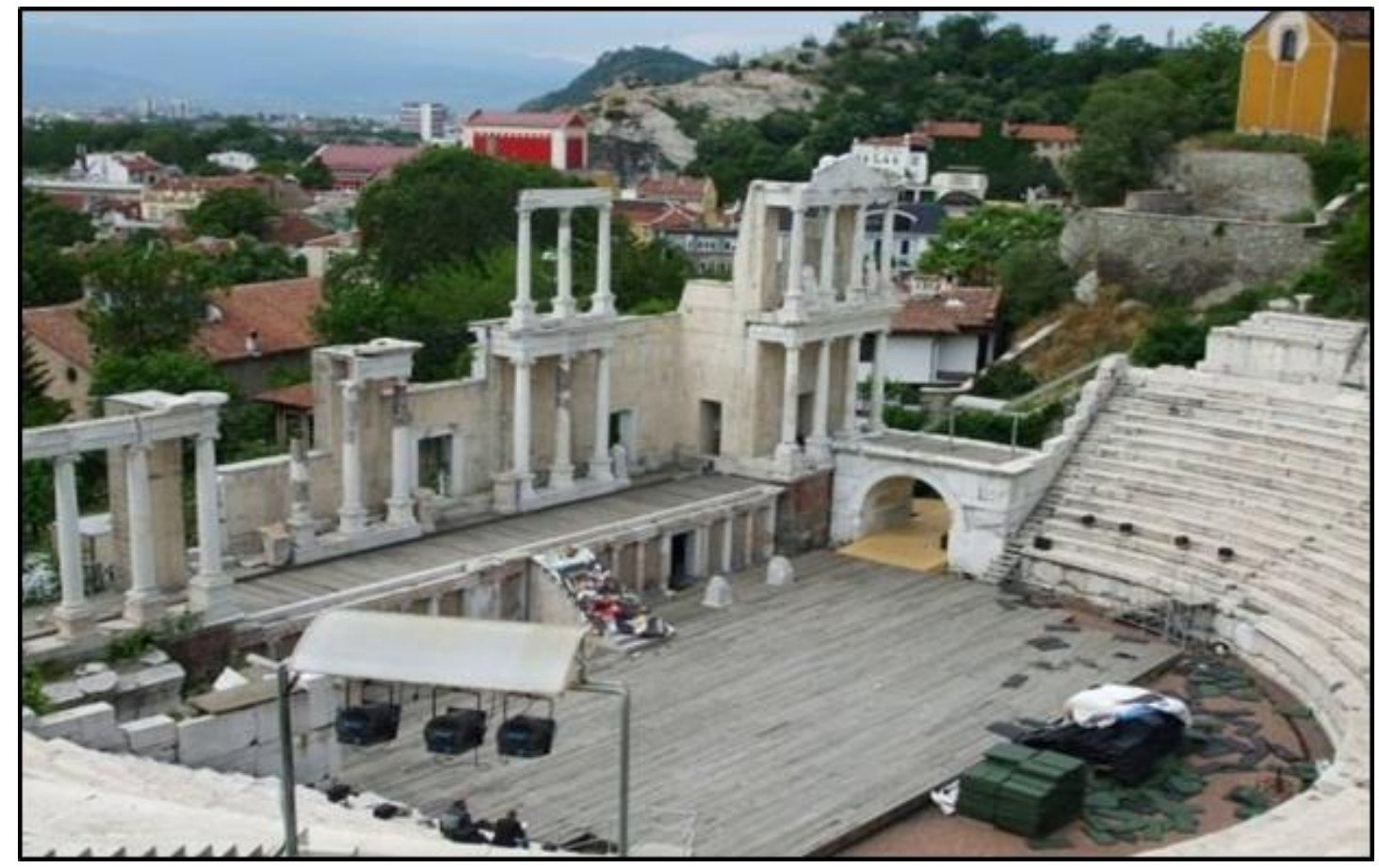

Fotoğraf 9. Antik Tiyatro'dan bir görünüm.

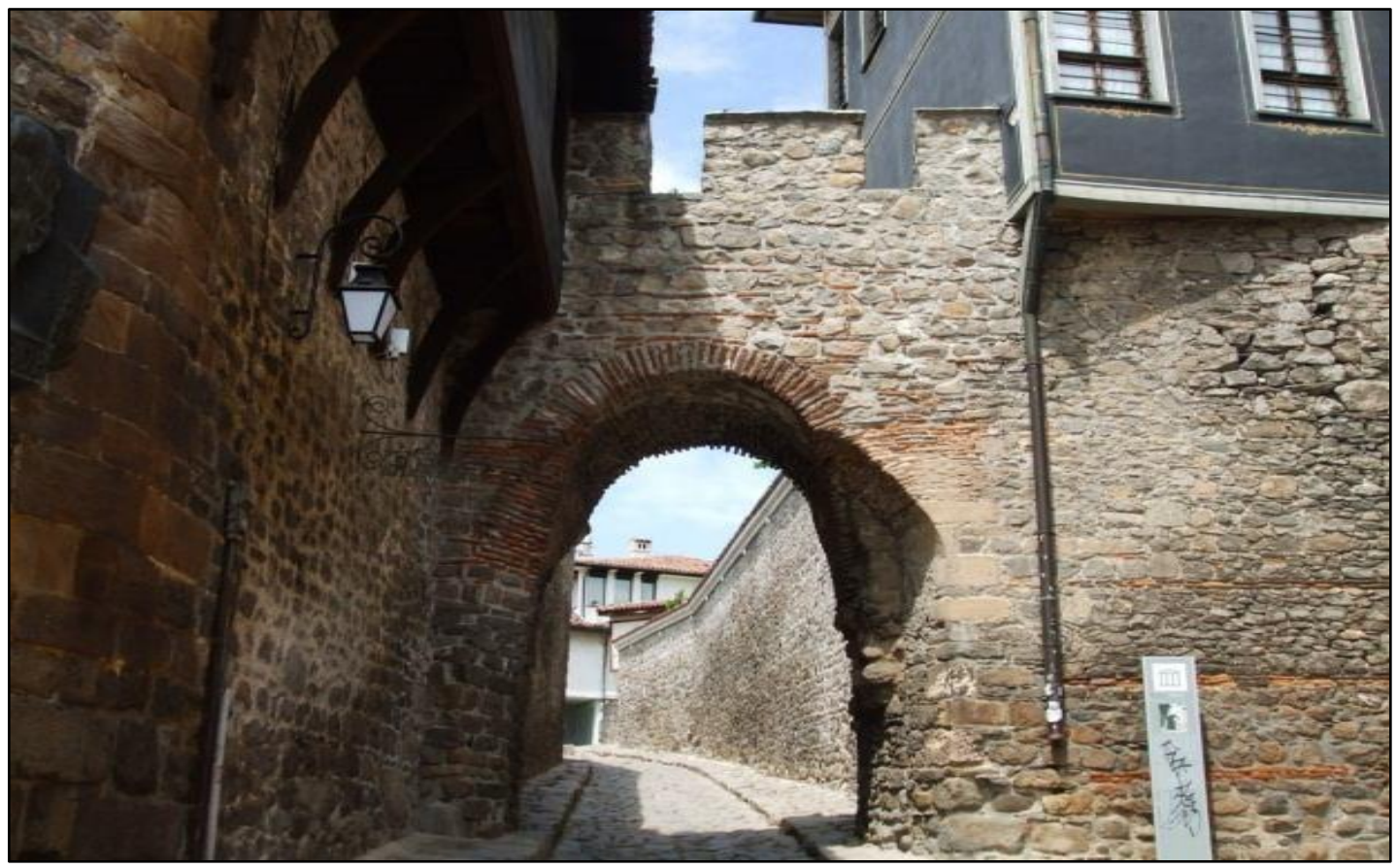

Fotoğraf 10. Hisar kapıdan bir görünüm. 